\title{
Using Evidence To Inform Practice and Policy To Enhance the Quality of Care for Persons with Traumatic Spinal Cord Injury
}

\author{
Michael G. Fehlings, Christiana L. Cheng,2 Elaine Chan, Nancy P. Thorogood,2 Vanessa K. Noonan, \\ Henry Ahn, ${ }^{3}$ Christopher S. Bailey, Anoushka Singh, and Marcel F. Dvorak ${ }^{6}$
}

\begin{abstract}
In today's economic climate, there is a need to demonstrate a return on investment for healthcare spending and for clinical practice and policy to be informed by evidence. Navigating this process is difficult for decision-makers, clinicians, and researchers alike. This article will describe how a knowledge translation framework and an evidence-based policy-making process were integrated to clarify the problem, frame options, and plan implementation, to impact clinical practice and policy in the area of traumatic spinal cord injury (tSCI). The Access to Care and Timing (ACT) project is focused on optimizing the access and timing of specialized healthcare delivery for persons sustaining a tSCI in Canada. A simulation model was developed that uses current patient data to address complex problems faced by the healthcare system. At a workshop, participants stressed the importance of linking interventions to short- and long-term outcomes to drive change. Presently, there are no national, system level indicators to monitor performance after tSCI. Although the ideal system of care after tSCI is unknown, indicator collection will establish a baseline to measure improvement. The workshop participants prioritized two indicators important from the clinician and patient perspective-timely admission to rehabilitation and meaningful community participation. The ACT simulation model for tSCI care will be used to promote the uptake of identified indicators and provide a predictive link between interventions on potential outcomes. The standardized collection of outcome-oriented indicators will help to evaluate the access and timing of care and to define the ideal system of care after SCI.
\end{abstract}

Keywords: indicators; policy making; practice change; specialized care; spinal cord injury

\section{Introduction}

$\mathbf{I}$ N TODAY'S ECONOMIC CLIMATE, there is a need to demonstrate a return on investment for healthcare spending by funding agencies, governments, and society as a whole. Worldwide, chronic disease is the major cause of mortality and accounts for $60 \%$ of all deaths globally. ${ }^{1}$ Traumatic spinal cord injury (tSCI) is one such chronic condition that, despite its relatively low incidence, maintains an estimated annual economic burden of $\$ 2.67$ billion in Canada alone. ${ }^{2}$

Persons who sustain a tSCI have increased healthcare service utilization $^{3-5}$ and higher rates of morbidity because of associated secondary health conditions, which can dramatically increase the cost of care. ${ }^{6-9}$ For example, the reported average cost attributed to hospital and community-acquired pressure ulcers in the SCI patient population ranges from approximately $\$ 18,500$ to more than $\$ 100,000$ per patient (2013 CAD), the upper boundary of which is nearly twice that of the average hospital population. ${ }^{10}$ Potential strategies to reduce this burden of care include the prevention/reduction of secondary health conditions, ${ }^{11,12}$ improvement in neurorecovery, ${ }^{13,14}$ efficiencies in triaging patients, ${ }^{15-17}$ and access to specialized care. ${ }^{17-21}$ Using a chronic disease model of care for the management of tSCI could change the system of care to support a patient's entire care continuum-to improve on how services are

\footnotetext{
${ }^{1}$ Department of Surgery, University of Toronto, Toronto, Ontario, Canada.

${ }^{2}$ Rick Hansen Institute, Vancouver, British Columbia, Canada.

${ }^{3}$ University of Toronto Spine Program, Toronto, Ontario, Canada.

${ }^{4}$ Division of Orthopaedics, Department of Surgery, Western University, London, Ontario, Canada.

${ }^{5}$ SCI Clinical Research Unit, Toronto Western Hospital, Toronto, Ontario, Canada.

${ }^{6}$ Department of Orthopaedics, University of British Columbia, Vancouver, British Columbia, Canada.
}

(C) Michael G. Fehlings et al., 2017; Published by Mary Ann Liebert, Inc. This Open Access article is distributed under the terms of the Creative Commons Attribution Noncommercial License (http://creativecommons.org/licenses/by-nc/4.0/) which permits any noncommercial use, distribution, and reproduction in any medium, provided the original author(s) and the source are credited. 
accessed and distributed, thereby increasing value by reducing costs and improving healthcare outcomes. ${ }^{12,22,23}$

The Access to Care and Timing (ACT) project is an example of a current health systems research project looking at healthcare delivery for persons sustaining a tSCI in Canada. It was hypothesized that patients with a tSCI who receive timely and specialized care will have superior patient outcomes and utilize fewer health resources compared with patients who experience delays and/or are treated in nonspecialized centers. The ACT project is an international, multi-center, multi-phased research study describing the processes of care, in pre-hospital, acute, rehabilitation, and community phases of care. ${ }^{24}$ The Knowledge to Action cycle ${ }^{25}$ was used in the ACT project as a framework to translate knowledge and make it "actionable" for policy-makers. ${ }^{24}$ With the need to assess return on investment, the ACT project used simulation modeling to answer complex problems faced by healthcare systems. The ACT Model can be used by decision-makers to assess the impacts of different "what if" scenarios at both the system and patient level. ${ }^{24,26,27}$ The ACT Model, however, is just a "tool," and for changes to occur at the policy level, it is important to use a framework developed specifically for this context for effective translation to occur.

Lavis and colleagues ${ }^{28-32}$ have outlined three steps in policymaking processes with examples of evidence and strategies for each step. Although policy-making processes differ, Lavis and colleagues $^{28-32}$ consider a systematic approach for policy-makers to use evidence and strategies to (1) clarify a problem, (2) frame options, and (3) plan implementation. This approach recognizes the importance of other factors such as the local context, resource availability, cost, capacity, cultural, social, and political accept-

\section{Evidence-Based Policymaking Process}

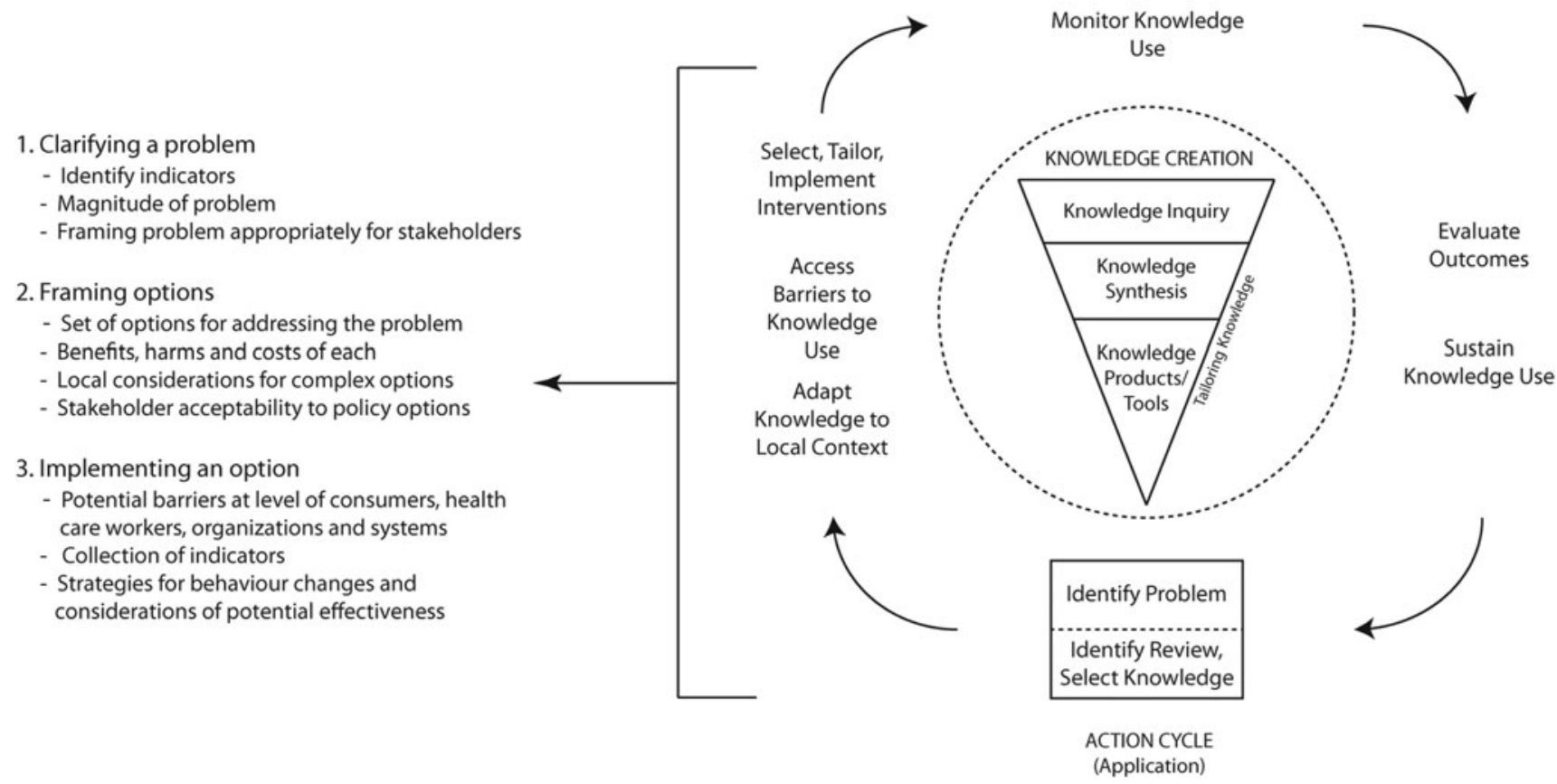

FIG. 1. Integration of Knowledge to Action cycle and evidence-based policy-making process. (Adapted from Lost in knowledge translation: Time for a map? Graham ID, et al Journal of Continuing Education in the Health Professions, 26. Copyright (C) 2006. The Alliance for Continuing Education in the Health Professions, the Association for Hospital Medical Education, and the Society for Academic Continuing Medical Education. Used with permission.) ability that must be considered by decision-makers. The approach proposed by Lavis and colleagues ${ }^{28-32}$ is consistent with other initiatives such as Evidence-Informed Policy Network, Health Systems Evidence, and Cochrane Collaboration. ${ }^{33-35}$

Connecting the Knowledge to Action Framework with the evidencebased policy process of Lavis and colleagues ${ }^{28-32}$ provides a unique The objective of this article is to describe how the evidence-based policy-making process of Lavis and colleagues ${ }^{28-32}$ was used in the ACT project across the SCI continuum of care to impact decisionmaking in Canada. This integrated approach was illustrated with two examples-timely admission to rehabilitation and meaningful community participation. While a Canadian context was used for the ACT project, we think that this work has broad international relevance for $\mathrm{SCI}$

\section{Overview of Application of the Evidence-Based Policy-Making Process of Lavis and Colleagues in the ACT Project}

The Knowledge to Action cycle (Fig. 1) divides translation into the concepts of knowledge creation and action. ${ }^{25}$ The knowledge creation phase is represented by a funnel where information is procured, synthesized, and refined so that it is relevant to stakeholders' needs and can assist with application of knowledge. The action phase is represented by a cycle with critical activities required to implement the knowledge and to provide feedback between activities. It is within the action cycle where the approach for evidence-based policy-making can be integrated (Fig. 1). ${ }^{28}$ The result of the knowledge creation phase can help to clarify the opportunity to ensure the best available evidence can influence policy.

\section{Knowledge to Action Cycle}

- Identify indicators

- Magnitude of problem

Framing options

Local considerations for complex options

Implementing an option

Potential barriers at level of consumers, health

Strategies for behaviour changes and

Academic Continuing Medical Education. Used with pernission.)
Clarifying a problem 
Clarifying a Problem
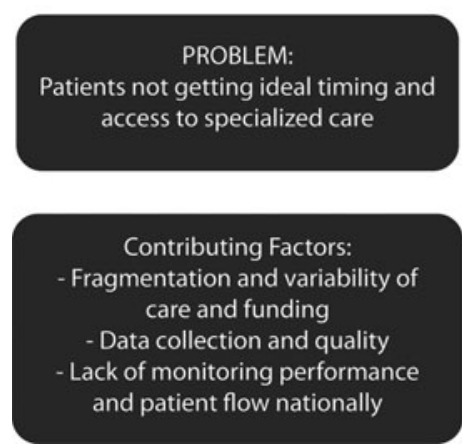

Framing Options
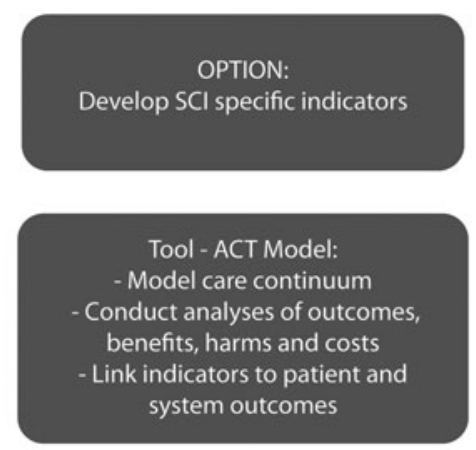

Implementing an Option (in progress)
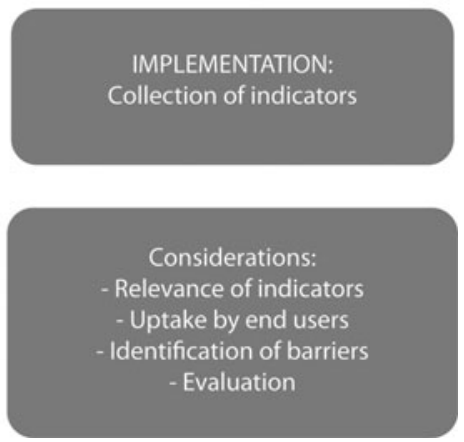

FIG. 2. Describing the Access to Care and Timing (ACT) project using an evidence-based policy-making framework. SCI, spinal cord injury.

problem, frame the options, and plan an implementation that is effective, based on evidence, and tailored to the needs of policy-makers.

The ACT project and simulation model demonstrate how integrating the Knowledge to Action cycle framework and the threestep evidence-based policy-making approach can inform SCI decision-making (Fig. 2). This approach is innovative in that it uses the knowledge creation phase to produce a simulation model that can be used as a tool in the policy-making process- to strengthen what is known and integrate it into the decision-making process by allowing scenarios and options to be viewed under the lens of the current healthcare system. Recently, there has been a push for clinical practice and policy change to be informed by evidence, but despite its importance, navigating the process is difficult for decision-makers, clinicians, and researchers alike. There is considerable evidence produced, but it is not always making its way into clinical practice or impacting patient health; moreover, there are patients also receiving care that is not based on current evidence. $^{25,36,37}$

The application of the evidence-based policy-making process of Lavis and colleagues ${ }^{28-32}$ to the ACT project is described below following the three steps: (1) clarify a problem, (2) frame options, and (3) plan implementation. ${ }^{28}$

\section{Clarifying the problem}

The focus of the ACT project deals with defining the importance of access and timing to specialized care for persons with tSCI. This focus was determined through consensus at an initial multidisciplinary stakeholder meeting. ${ }^{24}$ Factors preventing optimal access and timing to specialized care for persons with tSCI were identified as: variability and fragmentation of care; data collection and quality; and difficulties monitoring performance and patient flow. These factors were common across Canada, but the specifics were also unique to each facility and province.

Process mapping conducted at each ACT participating facility highlighted that: (1) nationally, there is variability in structures and services for persons with tSCI; and (2) there is fragmentation in care because hospital personnel and units often operated or were funded in isolated silos. ${ }^{24,38}$ Variability in care across Canada highlights that there are opportunities for improvement and shared learning across facilities. There is also a need to view the continuum of care as an integrated healthcare system because what occurs in one phase of care impacts other phases.

Data collection and quality issues, such as the lack of standardized data elements and limited availability of data on patient factors, were identified when developing the ACT Model. ${ }^{39} \mathrm{Be}-$ cause of these data issues, the ACT Model used multiple data sources including the Rick Hansen SCI Registry (RHSCIR), which is a pan-Canadian prospective observational registry of persons with $\mathrm{tSCI}^{40}$ literature review, subject matter experts, and other hospital and national databases.

At present in Canada, there are no national indicators to monitor performance and patient flow after tSCI. Although Accreditation Canada's Qmentum program for SCI prescribes that "indicator data is collected and used or guide quality improvement activities, ", specific indicators for this program have not been identified. ${ }^{41,42}$ Indicators are being developed, however, to assess the quality of care in both the fields of SCI and general trauma, and are led by groups such as AOSpine clinical guidelines for the management of acute SCI project, ${ }^{43}$ SCI Rehabilitation Care High Performance Indicators Project (SCI-HIGH), ${ }^{44}$ Accreditation Canada's Trauma Distinction Program, ${ }^{45}$ American College of Surgeons Trauma Quality Improvement Program, ${ }^{46,47}$ and the Quality of Trauma in Adult Care. ${ }^{48}$ Because tSCI is a subset of the trauma population, adaptation of selected indicators from Accreditation Canada's Trauma Distinction Program could be useful in measuring the tSCI system of care.

To work toward a solution for these problems related to access and timing to specialized care, a subsequent multi-disciplinary stakeholder meeting was held (the ACT Workshop in April 2014; Toronto, Ontario), ${ }^{49}$ which was attended by more than 80 participants, including persons with tSCI, clinicians, administrators, policy-makers, researchers, community partners, health economists, SCI-affiliated organizations, and national organizations. The workshop aimed to (1) disseminate knowledge from the ACT and other SCI and trauma-related projects; (2) highlight that the problem of access and timing to specialized care and its associated factors affects all stakeholders; and (3) obtain consensus on the indicators that should be adopted to mobilize national support to address the problem.

\section{Framing options}

At the ACT Workshop, indicators based on the Accreditation Canada's Trauma Distinction Program were proposed for tSCI. Participants discussed adapting these indicators for their validity in tSCI and made suggestions for metrics with data sources, data collection and reporting, and strategies to effectively engage patients and families.

Although the ideal system of care after tSCI is not known currently, ${ }^{17}$ collection of indicators will establish a baseline from which to measure improvement. National system level indicators 
can measure variability and fragmentation of care and highlight opportunities for improvement; motivate efforts to improve data collection and quality; and monitor health system performance through benchmarking. Consensus was reached among the participants on prioritizing two outcome-oriented indicators: rehabilitation onset days and meaningful participation in the community.

Results from the ACT Workshop stressed the importance of determining the impact of intervention on patient and healthcare system outcomes and linking indicators with outcomes to help drive policy and/or practice change, ${ }^{49}$ because indicators on their own do not measure quality of care. This could be achieved by employing the ACT Model designed to provide a predictive link between indicators and outcomes to estimate the benefits, harms, and costs of intervention for the healthcare system as well as for patients and families. Indicators will first require appropriate risk adjustment, however, to address the heterogeneity of tSCI and to account for differences between facilities; then the ideal threshold or benchmark of the indicator will need to be defined. Potential variables for risk adjustment for trauma indicators have been identified through literature review and statistical modeling. ${ }^{50,51}$

Another area of importance identified at the ACT Workshop was the need to enhance services for persons with SCI and their families to better guide them through the journey of care. Lessons can be learned from key components of the indicator work by the Quality of Trauma in Adult Care group who explored aspects of injury care important to patients and their families to help incorporate their perspectives into injury quality improvement. ${ }^{48,52}$

\section{Ongoing work on indicators}

The indicator, rehabilitation onset, is defined as the number of days between injury and rehabilitation admission. Timely admission to rehabilitation has been associated with shorter length of stay (LOS $)^{53}$ and improved patient outcomes in the SCI population. ${ }^{53-57}$ In addition, the onset of rehabilitation links across the care continuum because it is affected by the timing and management of care in the pre-hospital and acute phase. ${ }^{55-57}$ Rehabilitation onset days and the associated outcome of functional recovery using the Functional Independence Measure $(\mathrm{FIM})^{58}$ are currently collected by the RHSCIR. ${ }^{40}$

Rehabilitation onset days, however, have not been reported in a standard manner across all facilities participating in the RHSCIR. Work is under way to report risk-adjusted rehabilitation onset and FIM change to enable comparison of care between facilities in Canada. To further facilitate national benchmarking, opportunities are also being explored to standardize the definition of LOS. ${ }^{59}$ In addition, knowing the limitations of the FIM, initiatives to promote uptake of the SCI Independence Measure (SCIM), ${ }^{60}$ designed specifically for the SCI population, have been piloted at selected RHSCIR facilities. ${ }^{61}$ Future recommendations include documenting barriers for delay to assist in identifying ways to improve patient flow ${ }^{62,63}$ and mandating the report of this indicator to a national database (e.g., National Rehabilitation Reporting System) to increase sustainability of indicator collection.

Preliminary indicators for meaningful participation in the community were selected based on their alignment with Canadian

\section{A THE CURRENT STATE OF SCI CARE IN CANADA}

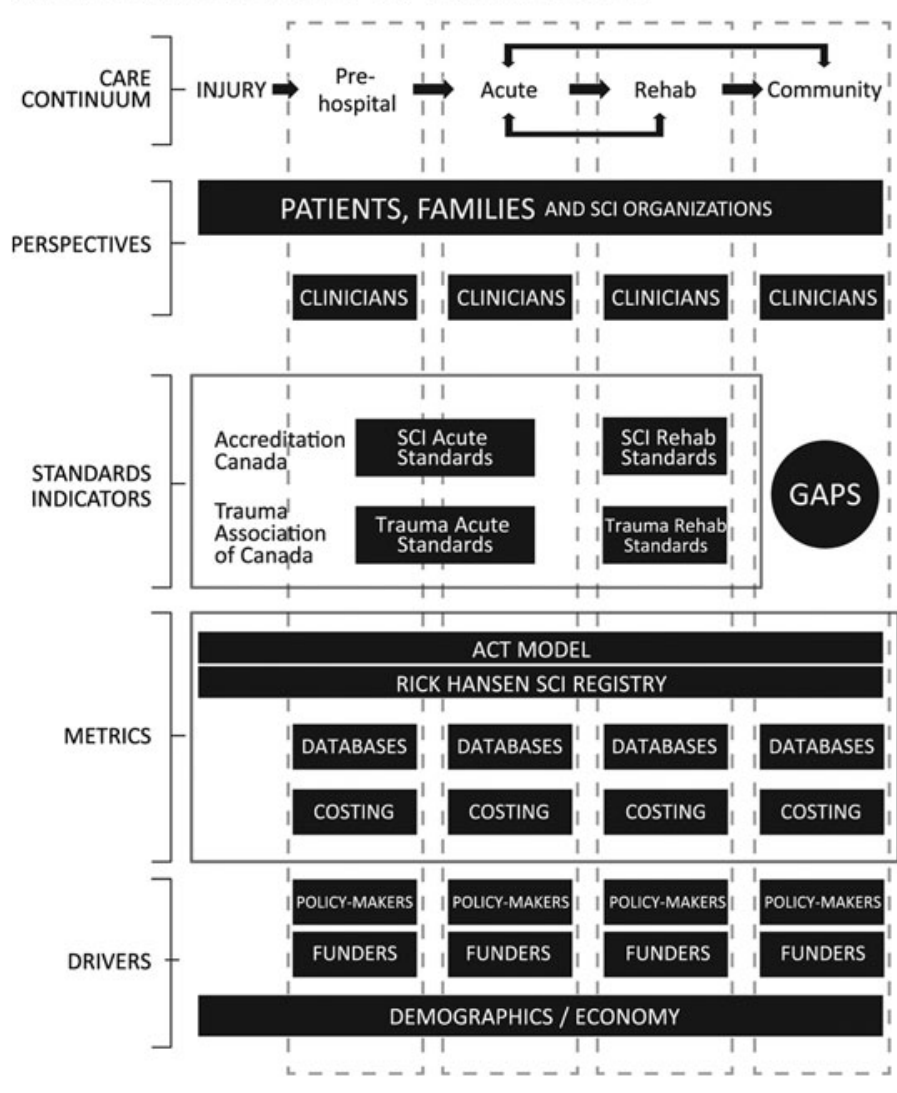

B THE PROPOSED FUTURE STATE OF SCI CARE IN CANADA
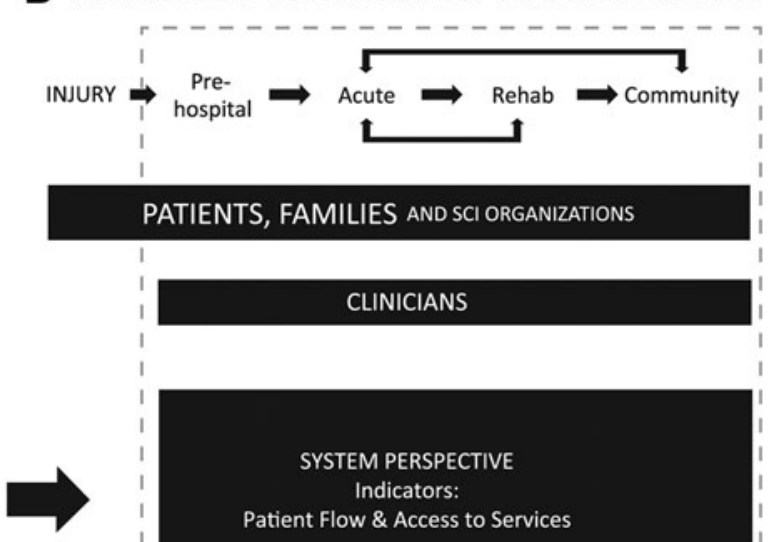

CLINICIANS

SYSTEM PERSPECTIVE Indicators:

Patient Flow \& Access to Services

FIG. 3. State of spinal cord injury care in Canada. Collaborative effort is needed to move from the segregated current state (A) to the proposed integrated future state (B). Reprinted from ACT Workshop Proceedings, 2014; published by Rick Hansen Institute, Vancouver, BC, Canada. SCI, spinal cord injury; ACT, Access to Care and Timing; CIHI, Canadian Institute for Health Information; DAD, Discharge Abstract Database; NRS, National Rehabilitation Reporting System; CCRS, Continuing Care Reporting System. 
clinician ${ }^{64}$ and patient ${ }^{65}$ priorities and were organized according to the International Classification of Functioning and Disability (ICF) framework with the addition of quality of life (QoL). ${ }^{66}$ Data elements to operationalize the ICF domains were (domains): demographics (Personal Factors); Short Form-36v $2^{67}$ emotional wellbeing (Body Function and Structures); FIM $^{58}$ (Activity); Life Satisfaction-11 Questionnaire ${ }^{68}$ sexual life scores and overall QoL scores (Participation and QoL); household income and employment status (Environmental Factors). These data elements are part of the RHSCIR Community Follow-up Questionnaire ${ }^{69}$ that captures longitudinal SCI information either by self-report or by an interviewer over an extended period post-injury; however, this questionnaire is operated within a research context. A RHSCIR pilot project in Alberta is enhancing the current model by collaborating with a SCI community organization (SCI Alberta) to integrate data collection with clinical service delivery so the results impact patients.

Recent work has highlighted the effect of secondary health conditions on community participation and long-term adjustment of persons with tSCI. ${ }^{70-73}$ Therefore, having additional indicators to monitor secondary health conditions and the clinical practice on preventing/treating these conditions will provide a measure of the underlying cause hampering meaningful participation and will identify opportunities to improve practice. Development of these indicators will align with the recommendations from the recent SCI Summits on secondary health conditions (pressure ulcers, neuropathic pain, and urinary tract infections/urological health); a common goal of these summits is to develop and implement evidence-based practice guidelines regionally and nationally. ${ }^{74}$

\section{Implementation planning}

The indicators described are two of the eight national system level indicators discussed at the ACT Workshop with the aim to consider and pilot the other six over time. Collection of these system indicators and other indicators examining SCI acute care $(\text { AOSpine })^{43}$ and rehabilitation care $(\mathrm{SCI}-\mathrm{HIGH})^{44}$ will assist in determining policy change options for improved care after tSCI. Addressing the issue of access and timing to specialized care in Canada and its associated factors by evaluating care from a system level perspective will lead to a more integrated continuum of care after tSCI and can shift the perspective toward patient-centered care, with emphasis on transition points and less focus on the particular phase of care (Fig. 3).

To assist with the efficient uptake of the indicator collection, inclusion of these system indicators will be considered for the revised Accreditation Canada SCI Standards; and facilities participating in the ACT project will be encouraged to take up these SCI Standards as part of their regular accreditation cycle. ${ }^{41,42}$ Further, a nationally coordinated strategy for indicator collection will allow facilities to demonstrate how meaningful indicators are selected, measured, and used to support evidence-based quality improvement.

Ensuring the relevance of the indicators and planning the implementation and evaluation of indicators will be important, because having a policy does not necessarily mean that it will be implemented efficiently or adopted into practice. Thus far, the ACT project has identified some challenges at the clinical, organizational, and systems levels that could influence the success of a downstream implementation plan. ${ }^{24,38}$ Challenges ranged from lack of resources, support, communication, and knowledge to limited availability of services and variation among jurisdiction, which might prove more difficult to intervene for policy change to occur. A collaborative model with na- tional stakeholders ${ }^{75}$ in a community of practice integrated with consumer voice ${ }^{76}$ by engaging community organizations will be crucial in tackling these challenges and advocating for change.

\section{Limitations}

A limitation with the evaluation of the ACT project and the ACT Model is that results and policy options only consider tSCI in isolation. In reality, persons with tSCI may have other associated traumatic injuries or health conditions that can impact treatment and outcomes. Another identified gap is not including nontraumatic SCI when developing the ACT Model. At the beginning of the project, it was decided to start with tSCI, because relatively more is known about the patient journey of tSCI compared with nontraumatic SCI; particularly complex is how persons with nontraumatic SCI enter into health system. Lessons learned from the tSCI population will inform expansion of the ACT Model for nontraumatic SCI.

\section{Conclusion}

Using an evidence-based policy-making process, the ACT project aims to improve timing and access to specialized care. Evaluation of the continuum of care through indicator collection will help to address timing and access to care, and its contributing factors, at a national level. By implementing indicators to monitor both patient flow and care, it will inform practice change and policy to define the ideal system of care after SCI.

\section{Acknowledgments}

The authors thank the Canadian Institutes for Health Research (CIHR), the Ontario Neurotrauma Foundation (ONF), and the Rick Hansen Institute for their financial support for the ACT Workshop; the ACT Workshop participants, and Barry White, B. Catherine Craven, Catherine Truchon, Chantal Graveline, Katharine Kovacs Burns, Kent Bassett-Spiers, Louise Russo, Lynne Moore, Mike Johnson, Ryan Metcalfe, Susan Jaglal, Suzanne Humphreys, Teren Clarke, and Tova Plashkes for their advice on the application of the ACT Model to inform care delivery.

This study was supported by financial contributions from the Rick Hansen Institute, the Ontario Neurotrauma Foundation, and the Government of Canada through Health Canada and Western Economic Diversification Canada.

\section{Author Disclosure Statement}

No competing financial interests exist.

\section{References}

1. World Health Organization. (2015). Chronic diseases and health promotion. Available at: www.who.int/chp/en/. Accessed July 1, 2015.

2. Krueger, H., Noonan, V.K., Trenaman, L.M., Joshi, P., and Rivers, C.S. (2013). The economic burden of traumatic spinal cord injury in Canada. Chronic Dis. Inj. Can. 33, 113-122.

3. Dryden, D.M., Saunders, L.D., Rowe, B.H., May, L., Yiannakoulias, N., Svenson, L.W., Schopflocher, D.P., and Voaklander, D.C. (2004). Utilization of health services following spinal cord injury: a 6-year follow-up study. Spinal Cord 42, 513-525.

4. Munce, S.E., Guilcher, S.J., Couris, C.M., Fung, K., Craven, B.C., Verrier, M., and Jaglal, S.B. (2009). Physician utilization among adults with traumatic spinal cord injury in Ontario: a population-based study. Spinal Cord 47, 470-476.

5. Guilcher, S.J., Munce, S.E., Couris, C.M., Fung, K., Craven, B.C., Verrier, M., and Jaglal, S.B. (2010). Health care utilization in nontraumatic and traumatic spinal cord injury: a population-based study. Spinal Cord 48, 45-50. 
6. DeVivo, M.J., Krause, J.S., and Lammertse, D.P. (1999). Recent trends in mortality and causes of death among persons with spinal cord injury. Arch. Phys. Med. Rehabil. 80, 1411-1419.

7. Krause, J.S., and Broderick, L. (2004). Patterns of recurrent pressure ulcers after spinal cord injury: identification of risk and protective factors 5 or more years after onset. Arch. Phys. Med. Rehabil. 85, 1257-1264.

8. Krause, J.S., Carter, R.E., Pickelsimer, E.E., and Wilson, D. (2008). A prospective study of health and risk of mortality after spinal cord injury. Arch. Phys. Med. Rehabil. 89, 1482-1491.

9. Cardenas, D.D., Hoffman, J.M., Kirshblum, S., and McKinley, W. (2004). Etiology and incidence of rehospitalization after traumatic spinal cord injury: A multicenter analysis. Arch. Phys. Med. Rehabil. 85, 17571763.

10. White, B.A., Dea, N., Street, J.T., Cheng, C.L., Rivers, C.S., Attabib, N., Kwon, B.K., Fisher, C.G., and Dvorak, M.F. (2016). The economic burden of urinary tract infection and pressure ulceration in acute traumatic spinal cord injury admissions: Evidence for comparative economics and decision analytics from a matched case-control study. J. Neurotrauma [Epub ahead of print].

11. DeVivo, M., and Farris, V. (2011). Causes and costs of unplanned hospitalizations among persons with spinal cord injury. Top. Spinal Cord Inj. Rehabil. 16, 53-61.

12. Guilcher, S.J., Craven, B.C., Lemieux-Charles, L., Casciaro, T., McColl, M.A., and Jaglal, S.B. (2013). Secondary health conditions and spinal cord injury: an uphill battle in the journey of care. Disabil. Rehabil. 35, 894-906.

13. Kwon, B.K., Okon, E., Hillyer, J., Mann, C., Baptiste, D., Weaver, L.C., Fehlings, M.G., and Tetzlaff, W. (2011). A systematic review of non-invasive pharmacologic neuroprotective treatments for acute spinal cord injury. J. Neurotrauma 28, 1545-1588.

14. Kwon, B.K., Okon, E.B., Plunet, W., Baptiste, D., Fouad, K., Hillyer, J., Weaver, L.C., Fehlings, M.G., and Tetzlaff, W. (2011). A systematic review of directly applied biologic therapies for acute spinal cord injury. J. Neurotrauma 28, 1589-1610.

15. Ahn, H., Singh, J., Nathens, A., MacDonald, R.D., Travers, A., Tallon, J., Fehlings, M.G., and Yee, A. (2011). Pre-hospital care management of a potential spinal cord injured patient: a systematic review of the literature and evidence-based guidelines. J. Neurotrauma 28, 1341-1361.

16. Bourassa-Moreau, É., Mac-Thiong, J.M., Feldman, D.E., Thompson, C., and Parent, S. (2013). Complications in acute phase hospitalization of traumatic spinal cord injury: does surgical timing matter? J. Trauma Acute Care Surg. 74, 849-854.

17. Parent, S., Barchi, S., LeBreton, M., Casha, S., and Fehlings, M.G. (2011). The impact of specialized centers of care for spinal cord injury on length of stay, complications, and mortality: a systematic review of the literature. J. Neurotrauma 28, 1363-1370.

18. DeVivo, M.J., Kartus, P.L., Stover, S.L., and Fine, P.R. (1990). Benefits of early admission to an organised spinal cord injury care system. Paraplegia 28, 545-555.

19. Ploumis, A., Kolli, S., Patrick, M., Owens, M., Beris, A., and Marino, R.J. (2011). Length of stay and medical stability for spinal cordinjured patients on admission to an inpatient rehabilitation hospital: a comparison between a model SCI trauma center and non-SCI trauma center. Spinal Cord 49, 411-415.

20. Yarkony, G.M., Bass, L.M., Keenan, V. III, and Meyer, P.R. Jr. (1985). Contractures complicating spinal cord injury: incidence and comparison between spinal cord centre and general hospital acute care. Paraplegia 23, 265-271.

21. Tator, C.H., Duncan, E.G., Edmonds, V.E., Lapczakl, L.I., and Andrews, D.F. (1995). Neurological recovery, mortality and length of stay after acute spinal cord injury associated with changes in management. Paraplegia 33, 254-262.

22. Coleman, K., Austin, B.T., Brach, C., and Wagner, E.H. (2009). Evidence on the Chronic Care Model in the new millennium. Health Aff. 28, 75-85.

23. Porter, M. (2010). What is value in health care. N. Engl. J. Med. 363, 2477-2481.

24. Noonan, V.K., Soril, L., Atkins, D., Lewis, R., Santos, A., Fehlings, M.G., Burns, A.S., Singh, A., and Dvorak, M.F. (2012). The application of operations research methodologies to the delivery of care model for traumatic spinal cord injury: the access to care and timing project. J. Neurotrauma 29, 2272-2282.

25. Graham, I.D., Logan, J., Harrison, M.B., Straus, S.E., Tetroe, J., Caswell, W., and Robinson, N. (2006). Lost in knowledge translation: time for a map? J. Contin. Educ. Health Prof. 26, 13-24.
26. Santos, A., Gurling, J., Dvorak, M.F., Noonan, V.K., Fehlings, M.G., Burns, A.S., Lewis, R., Soril, L., Fallah, N., Street, J.T., Bélanger, L., Townson, A., Liang, L., and Atkins, D. (2013). Modeling the patient journey from injury to community reintegration for persons with acute traumatic spinal cord injury in a Canadian centre. PLoS One 8, e72552.

27. Santos, A., Fallah, N., Lewis, R., Dvorak, M.F., Fehlings, M.G., Burns, A.S., Noonan, V.K., Cheng, C.L., Chan, E., Singh, A., Belanger, L.M., and Atkins, D. (2017). Methodology of access to care and timing simulation model for traumatic spinal cord injury. J. Neurotrauma Epub ahead of print

28. Lavis, J.N. (2009). How can we support the use of systematic reviews in policymaking? PLoS Med. 6, e1000141.

29. Lavis, J.N., Wilson, M.G., Oxman, A.D., Lewin, S., and Fretheim, A. (2009). SUPPORT Tools for evidence-informed health Policymaking (STP) 4: Using research evidence to clarify a problem. Health Res. Policy Syst. 7, Suppl 1, S4

30. Lavis, J.N., Wilson, M.G., Oxman, A.D., Grimshaw, J., Lewin, S., and Fretheim, A. (2009). SUPPORT Tools for evidence-informed health Policymaking (STP) 5: Using research evidence to frame options to address a problem. Health Res. Policy Syst. 7, Suppl 1, S5.

31. Lavis, J.N., Oxman, A.D., Lewin, S., and Fretheim, A. (2009). Health Research Policy and Systems SUPPORT Tools for evidence-informed health Policymaking (STP) 3: Setting priorities for supporting evidenceinformed policymaking. Health Res. Policy Syst. 7, Suppl 1, S3.

32. Fretheim, A., Munabi-Babigumira, S., Oxman, A.D., Lavis, J.N., and Lewin, S. (2009). SUPPORT Tools for Evidence-informed policymaking in health 6: using research evidence to address how an option will be implemented. Health Res. Policy Syst. 7, Suppl 1, S6.

33. World Health Organization. (2015). Evidence-informed policy network. Available at: global.evipnet.org/. Accessed April 26, 2017.

34. McMaster Health Forum. (2016). Health Systems Evidence. Available at: www.healthsystemsevidence.org/. Accessed Apr 26, 2017.

35. Cochrane Collaboration. (2015). Trusted evidence. Informed decisions. Better health. Available at: www.cochrane.org/. Accessed April 26, 2017.

36. McGlynn, E.A., Asch, S.M., Adams, J., Keesey, J., Hicks, J., DeCristofaro, A., and Kerr, E.A. (2003). The quality of health care delivered to adults in the United States. N. Engl. J. Med. 348, 2635-2645.

37. Grol, R. (2001). Successes and failures in the implementation of evidence-based guidelines for clinical practice. Med. Care 39, Suppl 2, II46-54.

38. Noonan, V.K., Chan, E., Santos, A., Soril, L., Lewis, R., Singh, A., Cheng, C.L., O'Connell, C., Truchon, C., Paquet, J., Christie, S., Ethans, K., Tsai, E., Ford, M., Drew, B., Linassi, A.G., Bailey, C.S., Fehlings, M.G., and RHSCIR Network. (2017). Traumatic spinal cord injury care in Canada: A survey of Canadian centres. J. Neurotrauma Epub ahead of print.

39. Dvorak, M.F., Cheng, C.L., Fallah, N., Santos, A., Atkins, D., Humphreys, S., Rivers, C.S., White, B.A., Ho, C., Ahn, H., Kwon, B.K., Christie, S., and Noonan, V.K. (2017). Spinal cord injury clinical registries: improving care across SCI care continuum by identifying knowledge gaps. J. Neurotrauma In press.

40. Noonan, V.K., Kwon, B.K., Soril, L., Fehlings, M.G., Hurlbert, R.J., Townson, A., Johnson, M., and Dvorak, M.F. (2012). The Rick Hansen Spinal Cord Injury Registry (RHSCIR): A national patientregistry. Spinal Cord 50, 22-27.

41. Accreditation Canada. (2017). Qmentum Program: Spinal Cord Injury Acute Services. Ottawa.

42. Accreditation Canada. (2017). Qmentum Program: Spinal Cord Injury Rehabilitation Services. Ottawa.

43. AOSpine. (2015). Research Knowledge Forum SCI 2015-Q3 Report. Available at: aospine.aofoundation.org/Structure/research/Knowledge Forum/kf-sci/Pages/kf-sci.aspx. Accessed May 17, 2017.

44. Craven, C. (2016). Establishing indicators for optimal spinal cord injury care - phase I: prioritization of rehabilitation domains. Presented at American Spinal Injury Association 2016 Annual Scientific Meeting. Philadelphia, PA.

45. Accreditation Canada. (2014). Trauma Distinction Information Package. Ottawa.

46. Shafi, S., Nathens, A.B., Cryer, H.G., Hemmila, M.R., Pasquale, M.D., Clark, D.E., Neal, M., Goble, S., Meredith, J.W., and Fildes, J.J. (2009). The Trauma Quality Improvement Program of the American College of Surgeons Committee on Trauma. J. Am. Coll. Surg. 209, 521-530.e1.

47. Nathens, A.B., Cryer, H.G., and Fildes, J. (2012). The American College of Surgeons Trauma Quality Improvement Program. Surg. Clin. North Am. 92, 441-454, x-xi. 
48. Santana, M.J., and Stelfox, H.T. (2014). Development and evaluation of evidence-informed quality indicators for adult injury care. Ann. Surg. 259, 186-192.

49. Chan, E., Cheng, C.L., and Noonan, V.K. (2014). Developing a national action plan to improve patient flow, access to services, and monitor health system performance in spinal cord injury care. $A C T$ Workshop Proceedings. Rick Hansen Institute: Vancouver, BC, Canada.

50. Stelfox, H.T., Santana, M.J., Lorenzetti, D., Clayden, N., and Sharp, C.M. (2013). Guide to Quality Indicators in Adult Trauma Care, Version 3. University of Calgary, AB, Canada.

51. Newgard, C.D., Fildes, J.J., Wu, L., Hemmila, M.R., Burd, R.S., Neal, M., Mann, N.C., Shafi, S., Clark, D.E., Goble, S., and Nathens, A.B. (2013). Methodology and analytic rationale for the American College of Surgeons Trauma Quality Improvement Program. J. Am. Coll. Surg. 216, 147-157.

52. Gagliardi, A.R., Boyd, J.M., Evans, D., Gerein, L., Nathens, A., and Stelfox, H.T. (2014). Establishing components of high-quality injury care: focus groups with patients and patient families. J. Trauma Acute Care Surg. 77, 749-756.

53. Sumida, M., Fujimoto, M., Tokuhiro, A., Tominaga, T., Magara, A., and Uchida, R. (2001). Early rehabilitation effect for traumatic spinal cord injury. Arch. Phys. Med. Rehabil. 82, 391-395.

54. Scivoletto, G., Morganti, B., and Molinari, M. (2005). Early versus delayed inpatient spinal cord injury rehabilitation: an Italian study. Arch. Phys. Med. Rehabil. 86, 512-516.

55. Heinemann, A.W., Yarkony, G.M., Roth, E.J., Lovell, L., Hamilton, B., Ginsburg, K., Brown, J.T., and Meyer, P.R. Jr. (1989). Functional outcome following spinal cord injury. A comparison of specialized spinal cord injury center vs general hospital short-term care. Arch. Neurol. 46, 1098-1102.

56. Celani, M.G., Spizzichino, L., Ricci, S., Zampolini, M., and Franceschini, M. (2001). Spinal cord injury in Italy: a multicenter retrospective study. Arch. Phys. Med. Rehabil. 82, 589-596.

57. Aito, S. (2003). Complications during the acute phase of traumatic spinal cord lesions. Spinal Cord 41, 629-635.

58. Keith, R.A., Granger, C. V, Hamilton, B.B., and Sherwin, F.S. (1987). The functional independence measure: a new tool for rehabilitation. Adv. Clin. Rehabil. 1, 6-18.

59. Burns, A.S., Santos, A., Cheng, C.L., Chan, E., Fallah, N., Atkins, D., Dvorak, M.F., Ho, C., Ahn, H., Paquet, J., Kwon, B.K., and Noonan, V.K. (2017). Understanding length of stay following spinal cord injury: insights and limitations from the access to care and timing (ACT) project. J. Neurotrauma Epub ahead of print.

60. Catz, A., Itzkovich, M., Agranov, E., Ring, H., and Tamir, A. (1997). SCIM-spinal cord independence measure: a new disability scale for patients with spinal cord lesions. Spinal Cord 35, 850-856.

61. Rick Hansen Institute. (2014). Spinal Cord Independence Measure (SCIM). Available at: sci2.rickhanseninstitute.org/scim. Accessed on April 26, 2017

62. Sharwood, L.N., Stanford, R., Middleton, J.W., Burns, B., Joseph, A., Flower, O., Rigby, O., Ball, J., and Dhaliwal, S. (2017). Improving care standards for patients with spinal trauma combining a modified eDelphi process and stakeholder interviews: a study protocol. BMJ Open 7, e012377.

63. New, P.W., Cameron, P.A., Olver, J.H., and Stoelwinder, J.U. (2013) Defining barriers to discharge from inpatient rehabilitation, classifying their causes, and proposed performance indicators for rehabilitation patient flow. Arch. Phys. Med. Rehabil. 94, 201-208.

64. Craven, C., Verrier, M., Balioussis, C., Wolfe, D., Hsieh, J., Noonan, V., Rasheed, A., and Cherban, E. (2012). Rehabilition environmental scan atlas: Capturing capacity in Canadian SCI rehabilitation. Vancouver: Rick Hansen Institute.
65. Noreau, L., Noonan, V.K., Cobb, J., Leblond, J., and Dumont, F.S (2014). Spinal Cord Injury Community Survey: a national, comprehensive study to portray the lives of Canadians with spinal cord injury. Top. Spinal Cord Inj. Rehabil. 20, 249-264.

66. Burns, A., Truchon, C., Graveline, C., Moore, L., Craven, B.C., and ACT Indicator National Working Group. (2015). Shaping the optimal continuum of care: using Canadian registry data to identify key community indicators after traumatic spinal cord injury. Presented at the 4th ISCoS and ASIA Joint Scientific Meeting. Montreal, Canada.

67. Ware, J.E., and Sherbourne, C.D. (1992). The MOS 36-item short-form health survey (SF-36). I. Conceptual framework and item selection. Med. Care 30, 473-483.

68. Fugl-Meyer, A.R., Branholm, I.B., and Fugl-Meyer, K.S. (1991). Happiness and domain-specific life satisfaction in adult northern Swedes. Clin. Rehabil. 5, 25-33.

69. Noreau, L., Cobb, J., Bélanger, L.M., Dvorak, M.F., Leblond, J., and Noonan, V.K. (2013). Development and assessment of a community follow-up questionnaire for the Rick Hansen spinal cord injury registry. Arch. Phys. Med. Rehabil. 94, 1753-1765.

70. Cobb, J., Dumont, F.S., Leblond, J., Park, S.E., Noonan, V.K., and Noreau, L. (2014). An exploratory analysis of the potential association between SCI secondary health conditions and daily activities. Top. Spinal Cord Inj. Rehabil. 20, 277-288.

71. Noonan, V.K., Fallah, N., Park, S.E., Dumont, F.S., Leblond, J., Cobb, J., and Noreau, L. (2014). Health care utilization in persons with traumatic spinal cord injury: the importance of multimorbidity and the impact on patient outcomes. Top. Spinal Cord Inj. Rehabil. 20, 289301.

72. Jetha, A., Dumont, F.S., Noreau, L., and Leblond, J. (2014). A life course perspective to spinal cord injury and employment participation in Canada. Top. Spinal Cord Inj. Rehabil. 20, 310-320.

73. Rivers, C.S., Fallah, N., Noonan, V.K., Whitehurst, D.G., Schwartz, C., Finkelstein, J., Craven, B.C., Ethans, K., O'Connell, C., Truchon, C., Ho, C., Linassi, A.G., Short, C., Tsai, E., Drew, B., Ahn, H., Dvorak, M.F., Paquet, J., Fehlings, M.G., Noreau, L., and the RHSCIR Network. (2017). Health conditions: impact on function, health-related quality of life, and life satisfaction following traumatic spinal cord injury. A prospective observational registry cohort study. Arch. Phys. Med. Rehab [Epub ahead of print].

74. Rick Hansen Institute. (2016). RHI and ONF partner to support three leading SCI summits this November. Available at: www.rickhanseninstitute .org/resource/publications-media/news-events. Accessed April 26, 2017.

75. Rick Hansen Institute. (2013). CARE program. Available at: rickhan seninstitute.org/images/stories/Article_PDFs/Care_Roadmap_4MAR14 .pdf. Accessed April 9, 2017.

76. Rick Hansen Institute. (2015). Consumer Program. Available at: www .rickhanseninstitute.org/work/programs/consumer. Accessed April 26, 2017.

Address correspondence to:

Michael G. Fehlings, MD, PhD

Department of Surgery

University of Toronto

399 Bathurst Street, Suite 4ww-449

Toronto, Ontario

M5T 2S8 Canada

E-mail: Michael.Fehlings@uhn.ca 